\title{
HISTORICAL DIALOGUE
}

\section{Conceptualizing and Mapping a Field}

\author{
Ariella Lang \\ Columbia University \\ al223@columbia.edu
}

\begin{abstract}
This Introduction provides an overview of the term historical dialogue, and its relationship to the fields of transitional justice, memory studies, peacebuilding and conflict transformation. In considering the challenges facing post-conflict societies, the author suggests ways in which these different fields respond to a wide range of challenges that the legacy of violence incurs. With a particular focus on historical dialogue, and the ways in which historical dialogue is framed within the issue, Lang proposes considering history itself as a form of advocacy and an integral component of peacebuilding.
\end{abstract}

\section{Keywords}

conflict transformation; dealing with the past; historical dialogue; peacebuilding

\section{About the Author}

Ariella Lang has published in the fields of Holocaust and genocide studies, historical memory, and minority rights and cultures. She currently teaches at Columbia University, where she also serves as Associate Dean of Academic Affairs. 
In exploring the ways in which the term "historical dialogue" might be used in different disciplines, and what the relationship is between historical dialogue and fields such as transitional justice, memory studies, peacebuilding and conflict resolution, this Forum Kritika on Historical Dialogue of Kritika Kultura considers how experts understand the term "historical dialogue," and how their work engages with issues related to the legacy of historical violence and its ties to contemporary politics. The role of historical narratives in politics and policies lies at the heart of historical dialogue. Indeed, in terms of conceptual boundaries, historical dialogue engages with the legacy of historical violence in conflict, post-conflict and postdictatorial societies, and the recognition that many contemporary conflicts germinate from the memory of past violence. It is, in this sense, very much part of the field of conflict transformation and prevention. In other ways, historical dialogue crosses into the field of human rights, conveying as it does an aspirational norm that is informed by a set of international rights, including (but not limited to) the right to truth and the right to redress.

The focus of historical dialogue on the legacy of mass violence and the ways in which this violence is remembered by the communities who experienced it-and by communities I mean to include both perpetrators and victims, both those who lived the experience and those for whom the experience might be inherited-speaks to its unique position as an area of scholarship and practice that should be considered an essential method to better understand the roots of deeply entrenched, identitybased conflicts, their aftermaths, and practical considerations of what might be done to address them. In so doing, historical dialogue seeks to enable groups in conflict with one another to acknowledge opposing narratives about the past, and thereby to facilitate the construction of a new public culture that has the ability to shape stronger civic and democratic processes.

Very often, perhaps as a result of its interdisciplinary identity, historical dialogue is defined by what it is not, and two such instances exemplify this fact: first, it is quite different from the general tendency of conflict transformation studies, in which the past is often seen as something that should be set aside as a precondition to creating a better future. That is not to say that the importance of the past is denied. It is indeed, if anything, quite the opposite: history is treated gingerly because of a recognition of its ability to stir the flames of a divisive discourse that might reignite tensions. As scholar Barbara Tint writes, "we are still operating with limited ability to infuse our present interventions with appropriate and relevant connections to how conflict parties have internalized their lived or learned history" (240). History and the way it is remembered, in other words, are not integrated components within mainstream conflict resolution discourses, and history is often seen as a liability even if its importance is acknowledged. Consequently, conflicting narratives about the past-the ways that past events are remembered by different 
groups, the ways in which communities in conflict have interpreted and taught a certain history to their members-are held at arm's length from the central components in reconciliation processes.

In contrast, historical dialogue is predicated upon the belief that the memory of past violence has a central impact on contemporary politics, and consequently must be a central component in any consideration of how to address the legacy of violence and the intellectual, social, and political responses that make up such initiatives. Historical dialogue thus promotes scholarship and societal discourse about the past and focuses on questions of collective identity that support the long-term transformation of societies and that requires a thorough examination of the past and the way it is remembered. Through a careful examination of official historical narratives, for example, historical dialogue seeks to identify, contest, and dismantle nationalist myths and identities. In some ways, this work is tied to the intractability of identity-based conflict, in which the denial of a particular identity is itself often identified as the origin of the conflict, and this existential threat occupies a central space in the communal memory of this group, such that it becomes an integral part of the communal identity (Tint 245).

Hannah Arendt once wrote of the need to set aside "not the memory, but the continuing hostility and the need for retribution associated with the memory of the painful past" (qtd. in Tint 251). This statement succinctly states one of the primary objectives of historical dialogue in its work in engaging opposing sides of the conflict, and there are many examples of what forms such engagement might take-none of them easy, but all of them vital contributions to the possibility of deescalating tensions and creating opportunities for former adversaries to reconsider their relationship with the other: the acknowledgement of responsibility and guilt for a crime and the acknowledgement of victims of past violence; challenging instances of denial as well as national or ethnic memories of heroism and/or victimhood; promoting efforts at understanding the past that counter assumptions that opposing sides of a conflict must view conflict as a zero-sum rivalry; enhancing the public discussion about the past; among many others.

In this sense too, scholars and practitioners of historical dialogue work in a field that is quite distinct from the field of transitional justice. Unlike transitional justice, historical dialogue focuses on non-judicial processes, and in particular on the collective memories of conflict. The collective memory of conflict, with its emphasis on community, also means that historical dialogue focuses on longterm transformation that may involve communities immediately emerging from conflict, but could just as easily involve communities that are dealing with a legacy of violence that recedes much further into the past (indeed that might not have any living witnesses associated with it). Thus, for example, historical dialogue 
mechanisms can be used in the context of the Balkan wars of the 1990s, where nationalist propaganda continues to present a challenge to initiatives that seek to deal with the past; but they can also be used to consider the Armenian genocide and Turkey's refusal to acknowledge it as such, even though we are almost 100 years from the event itself, and all the stakeholders at the time are no longer alive.

In these very different historical contexts, then, historical dialogue focuses on acknowledging the central role of history in understanding conflict, on exploring restorative action at the group level (e.g. museums, memorials, reparations, redress), all with the goal of engaging opposing sides in a critical understanding of the past that enables all or both sides of a conflict to recognize multi-perspectival understandings of the past (i.e. shared narratives) that, while certainly open to disagreement and multiple interpretations, seek to ensure that such disagreements do not escalate the conflict once again in prescribed terms where opinions are divided along identity lines. As Sarah Maddison argues, reconciliation should be seen as seen as a long-term process that allows community members to disagree strongly, but that "rests on respect for the other as a moral equal, allowing members of a community to see themselves as part of a shared community." The expectation, then, is that historical dialogue contributes to conflict transformation by fostering understanding for alternative perspectives and facilitating the construction of a new perception of the past.

Thus, the goal of historical dialogue is to counter the manipulation of history and the antagonistic representation of historical violence that results from attempts to promote identities that themselves contribute to increased tension and hostilities among identity groups, fomenting vengeance and a spiraling pattern of violence. The four papers contained herein speak in very different ways to these objectives. In her interviews with practitioners who engage in memory work in Northern Ireland and East Africa respectively, Sara Dybris McQuaid's exploration (with Henrik Sonne Petersen and Johnston Price) of the role of historical dialogue allows readers to consider historical dialogue projects taking place on the community level. In his exploration of memory politics and gay victims of Nazis Germany, Arnaud Kurze maps the history of memory politics and memorialization processes for sexual minorities in Germany. With his focus on sites of memory, the essay allows readers to consider the ways in which a specific historical dialogue mechanism has contributed to a growing acknowledgement of a formerly taboo and censored category of victims. In writing on the 1965 genocide in Indonesia, Kar-Yen Leong suggests the ways in which historical dialogue mechanisms can serve as a mode for dealing with a violent past in a context where justice and accountability continue to be elusive. Finally, in their joint paper on the Mapping Historical Dialogue Project (MHDP), Alison Atkinson-Phillips, Ulrike Capdepón, Jill Strauss, and Oriol López-Badell explore their work as both scholars and practitioners, considering 
their contributions to discreet historical dialogue projects in a variety of national and/or regional contexts, as well as their work on a digital project that seeks more broadly to capture the discourse of historical dialogue and, in so doing, to consider its impact. As a collection of essays, the diversity of contexts in which historical dialogue work is being done is noteworthy, as is the wide range of places in which this work is being conducted. And in this sense, the works of these authors are of particular significance, since they provide a more comprehensive understanding of the depth of the field, and allow readers to consider how and how well historical dialogue impacts conflict transformation, reconciliation, and peacebuilding processes. 


\section{Works Cited}

Maddison, Sarah. "Transforming Conflict: The Challenge of Political Reconciliation." Australian Broadcasting Corporation, 24 Nov. 2016, https://www.abc.net.au/religion/ transforming-conflict-the-challenge-of-political-reconciliation/10o96312. Accessed 6 Nov. 2018.

Tint, Barbara. "History, Memory and Intractable Conflict." Conflict Resolution Quarterly, vol. 27 , no. 3, 2010, pp. 239-256. 